Viso - Cadernos de estética aplicada Revista eletrônica de estética

ISSN 1981-4062

No 22, jan-jun/2018

http://www.revistaviso.com.br/

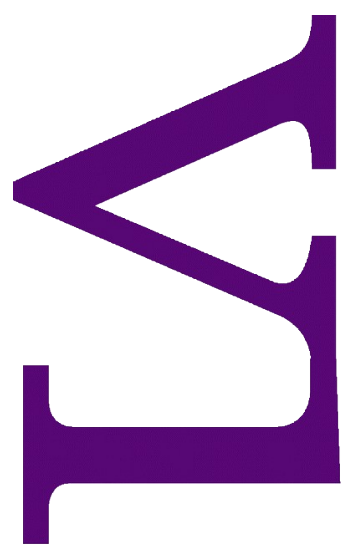

N

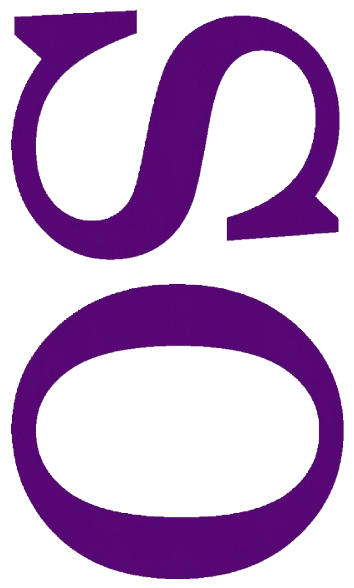

\title{
Entre $O$ mito de Sísifo e Sambas do absurdo: a possibilidade de revelar o absurdo através do samba Vinicius Xavier Hoste
}




\section{RESUMO}

Entre O mito de Sísifo e Sambas do absurdo: a possibilidade de revelar o absurdo através do samba

O intento deste artigo é pensar a relação que o ensaio $O$ mito de Sísifo - publicado em 1942 por Albert Camus - e o disco Sambas do Absurdo - lançado em 2017 pelo trio: Rodrigo Campos, Juçara Marçal e Gui Amabis - mantém com o absurdo. A fim de iluminar essa relação, buscaremos apresentar, em primeiro lugar, o que seria o absurdo para Camus; para isso, percorreremos, principalmente, o caminho traçado pelo autor em O mito de Sísifo. Em seguida, tentaremos mostrar como essa teoria do absurdo ecoa nas mais diversas camadas de Sambas do Absurdo. Por fim, gostaríamos ainda de ressaltar como o disco não é uma tentativa de "musicar a teoria", quer dizer, ele não tenta simplesmente oferecer ao ouvinte um comentário, uma exegese da teoria do absurdo, ao invés disso, Sambas do Absurdo se afirma enquanto obra, construindo absurdos próprios.

Palavras-chave: filosofia - arte - samba - absurdo - Camus

\section{ABSTRACT}

Between The Myth of Sisyphus and Sambas do absurdo: The Possibility of Revealing the Absurd through Samba

The purpose of this article is to think about the relation that the essay The myth of Sisyphus - published in 1942 by Albert Camus - and the album Sambas do Absurdo released in 2017 by the trio: Rodrigo Campos, Juçara Marçal and Gui Amabis - maintains with the absurd. In order to illuminate this relationship, we will try to present, in the first place, what would be the absurd for Camus; for this, we will walk, mainly, the path traced by the author in The myth of Sisyphus. Then we shall try to show how this theory of the absurd echoes in the most diverse layers of Sambas do Absurdo. Finally, we would like to emphasize how the album is not a transformation of Camus's theory into music, that is, it does not simply try to offer the listener a comment, an exegesis of the theory of the absurd, instead, Sambas do Absurdo affirms itself constructing their own absurdities.

Keywords: philosophy - art - samba - absurd - Camus 
HOSTE, V. X. "Entre O mito de Sísifo e Sambas do absurdo: a possibilidade de revelar o absurdo através do samba". In: Viso: Cadernos de estética aplicada, v. XII, n. 22 (jan-jun/2018), pp. 160-179.

DOI: $10.22409 / 1981-4062 / v 22 i / 245$

Aprovado: 06.04.2018. Publicado: 30.06.2018.

(C) 2018 Vinicius Xavier Hoste. Esse documento é distribuído nos termos da licença Creative Commons Atribuição-NãoComercial 4.0 Internacional (CC-BY-NC), que permite, exceto para fins comerciais, copiar e redistribuir o material em qualquer formato ou meio, bem como remixá-lo, transformá-lo ou criar a partir dele, desde que seja dado o devido crédito e indicada a licença sob a qual ele foi originalmente publicado.

Licença: http://creativecommons.org/licenses/by-nc/4.0/deed.pt_BR

Accepted: 06.04.2018. Published: 30.06.2018.

(C) 2018 Vinicius Xavier Hoste. This document is distributed under the terms of a Creative Commons Attribution-NonCommercial 4.0 International license (CC-BY-NC) which allows, except for commercial purposes, to copy and redistribute the material in any medium or format and to remix, transform, and build upon the material, provided the original work is properly cited and states its license.

License: http://creativecommons.org/licenses/by-nc/4.0/ 
O mito de Sísifo foi publicado na França no ano de 1942, ou seja, em meio à segunda guerra mundial, período de questionamentos diante das absurdidades que a guerra então revelava. Sambas do absurdo ${ }^{1}$ foi lançado nas plataformas digitais no dia 28 de abril de 2017, dia de greve geral no Brasil, dia de protestos contra a perda de direitos básicos, contra reformas abusivas e absurdas impostas pelo governo brasileiro. O disco se inspira na obra de Camus, na teoria do absurdo apresentada em O mito de Sísifo, mas não só; ele também tem como referência o absurdo vivido, experimentado por cada um de nós - hoje. Por conseguinte, não se deve pensar que esses "sambas" tentem simplesmente traduzir o sentido da teoria, isto é, transformar a concepção do absurdo em canção; na verdade, o disco busca desenvolver novos sentidos para essa concepção, sentidos que se dão a partir da nossa realidade e que se revelam através de uma estética do absurdo. Nessa perspectiva, mesmo diante de uma separação não só contextual, mas também discursiva entre o ensaio filosófico e o disco, as duas obras compartilham uma mesma finalidade: iluminar o absurdo.

A questão que se coloca então é: como a arte poderia constituir uma via para se abordar um problema originalmente filosófico?

Segundo Camus ${ }^{2}$, não existe uma separação absoluta entre arte e filosofia, dado que as tarefas do artista e do filósofo se assemelham. Ambos partilham um mesmo objetivo: oferecer um limiar de sentido, uma visão de mundo. Certamente, cada uma dessas disciplinas terá um clima característico, um discurso próprio, um estilo singular de apresentar e de construir esse sentido, no entanto, nesse caminho de construção de sentido é possível que esses "climas" se misturem e se confundam. De fato, se observarmos a obra do próprio Camus, não encontraremos uma oposição entre filosofia e arte, pelo contrário, o autor se vale de ambas para apresentar sua visão de mundo. Em O mito de Sísifo, por exemplo, mais do que tentar explicar logicamente o absurdo, Camus procura ilustrá-lo, isto é, "ilustrar a condição humana"3; por isso, em vários momentos do ensaio ele utiliza ficções ${ }^{4}$ a fim de mostrar aquilo que a conceituação filosófica talvez não fosse capaz de transmitir.

A esse respeito, Onfray ${ }^{5}$ nos explica que o pensamento camusiano não se caracteriza enquanto uma "filosofia filosofante", isto é, enquanto uma reflexão que tenta demarcar o terreno filosófico e separar-se de qualquer pretensão estética, mas enquanto uma "filosofia literária", ou seja, enquanto uma filosofia que se desenvolve através de uma "[...] prosa elegante, clara, precisa, estética, que não sacrifica o sentido, a profundidade e a verdade pela forma". Inversamente, enquanto artista, Camus constrói uma prosa literária que é uma espécie de "literatura filosófica", já que seus romances, como esclarece Onfray,

[...] não se propõem ao jogo literário da distração, da disposição formal, da arte pela arte, mas formulam a visão de um mundo exterior às ideias e aos conceitos, com a ajuda de personagens, narrativas, histórias, aventuras fictícias. ${ }^{6}$ 
Ora, se na obra de Camus a filosofia se vale de meios estéticos a fim de apresentar uma visão de mundo, inversamente, na sua arte ele também se vale da filosofia para construir um sentido. Diante disso, não parece um disparate dizer que Sambas do absurdo pode se valer da teoria filosófica do absurdo a fim de construir representações não necessariamente filosóficas sobre esse tema.

Dito isso, gostaríamos de pensar agora como uma obra filosófica e uma obra de arte podem abordar um problema comum - o absurdo - a partir de linguagens diferentes, oferecendo, contudo, reflexões igualmente profundas. São justamente essas reflexões que buscaremos iluminar a partir daqui, não a fim de exauri-las, mas simplesmente de reivindicar uma interpretação possível.

\section{O despertar do absurdo}

Em uma situação qualquer, dizer que algo é absurdo é dizer que aquilo não condiz com a realidade, que é contraditório, desproporcional, impensável. Nesse sentido, o absurdo depende tanto do homem quanto do mundo, pois sua aparição só pode acontecer a partir de uma disparidade, de uma incompatibilidade, de um confronto entre a razão humana e a irracionalidade mundana: "O absurdo nasce desse confronto entre o apelo humano e o silêncio irracional do mundo" - diz Camus. Ora, sendo o absurdo gerado por uma relação conflituosa entre o homem e o mundo, isso significa que ele desaparecerá caso um dos termos dessa relação desapareça. Dito de outro modo, o absurdo não está nem no homem nem no mundo, mas justamente na relação entre eles, na luta incessante que travam.

Isso quer dizer que se o homem fosse como as árvores ou como as pedras, por exemplo, esse confronto não existiria, visto que não haveria nenhuma oposição, nenhuma separação, mas apenas uma homogeneidade na qual não restaria espaço para o absurdo. Todavia, tal homogeneidade é inalcançável, pois há uma distância intransponível entre homem e mundo, de modo que, mesmo podendo manter uma proximidade íntima, mesmo podendo permanecer "apoiados um no outro", eles jamais conseguirão se abraçar verdadeiramente.

A partir dessa pequena consideração, é possível notar que o absurdo não é um fenômeno extraordinário, pelo contrário, como escreve Guimarães: "Num breve instante podemos nos dar conta deste absurdo e, sempre, em situações caracterizadas pela insignificância". ${ }^{8}$ Quer dizer, qualquer homem a qualquer momento está sujeito a tomar ciência da absurdidade de uma situação, apreendendo assim a densidade, a irracionalidade, a estranheza do mundo. De fato, segundo Camus, um simples "porquê" basta para desencadear a consciência do absurdo: 
Acordar, bonde, quatro horas no escritório ou na fábrica, almoço, bonde, quatro horas de trabalho, jantar, sono e segunda terça quarta quinta sexta e sábado no mesmo ritmo, um percurso que transcorre sem problemas a maior parte do tempo. Um belo dia, surge o "porquê" e [...] inaugura ao mesmo tempo o movimento da consciência. ${ }^{9}$

Quer dizer, de uma hora para outra a aparente familiaridade que o mundo apresenta pode desmoronar e tudo que parecia inquestionável pode assumir um caráter insólito e hostil, pois diante da irrevogável lógica do absurdo toda certeza se abala. No homem que vislumbra o caráter indecifrável do mundo "[...] o sentimento do absurdo se esclarece" ${ }^{10}$, de modo que ele reconhece que a existência é, em sua própria natureza, absurda.

Nesse contexto, até mesmo o conhecimento - aparentemente capaz de tudo solucionar - perde seu valor absoluto e se dissolve diante da enorme distância existente entre aquilo que experimentamos na vivência concreta e aquilo que podemos verdadeiramente conhecer. O absurdo mostra que se, por um lado, é possível descrever os fenômenos da natureza, classificá-los em diferentes grupos e até mesmo elencar suas leis, por outro, esses procedimentos são apenas formas de estruturar os mecanismos do mundo e não de solucioná-los: o mundo pode ser experienciado, mas está sempre para além do conhecimento.

Com efeito, para Camus, o conhecimento oferece apenas descrições hipotéticas, incertas e, muitas vezes, paradoxais do mundo:

[...] vocês me ensinam que este universo prestigioso e multicolor se reduz ao átomo e que o próprio átomo se reduz ao elétron. Tudo isto é bom e espero que vocês continuem. Mas me falam de um sistema planetário invisível em que os elétrons gravitam ao redor de um núcleo. Explicam-me este mundo com uma imagem. Então percebo que vocês chegaram à poesia: nunca poderei conhecer. ${ }^{11}$

O absurdo revela assim um caráter "poético" do conhecimento, pois não pode haver uma verdade absoluta sobre o mundo, mas verdades múltiplas, mutáveis e, sobretudo, aproximativas. Destarte, ao invés de assegurar o homem de seu destino, a pretensão de tudo conhecer acaba por acentuar o caráter irracional e obscuro que esse destino apresenta. Na tentativa de reduzir o mundo a fórmulas e conceitos, o conhecimento só faz iluminar sua irredutibilidade. Como coloca Camus, as fórmulas científicas "[...] podem ser válidas até um certo limite, ultrapassado o qual elas se voltam contra si mesmas e fazem nascer o absurdo". ${ }^{12}$

Ora, as considerações que fizemos até aqui sobre absurdo não se pretendem definições, mas são apenas tentativas de descrever algumas maneiras como o sentimento do absurdo pode se manifestar - restando ainda muitas outras. Outra dessas maneiras é o tempo. Segundo Camus ${ }^{13}$, no cotidiano, o tempo nos carrega silenciosamente, de uma maneira quase imperceptível. No entanto, apesar dessa sutileza, existe sempre um momento em que devemos carregá-lo: surge aí a possibilidade de que nos situemos em relação a ele, isto é, de que vislumbremos que altura da estrada ele percorre, de que 
percebamos quanto falta até o fim do caminho. Há nesse situar-se o reconhecimento do nosso pertencimento ao tempo: ver-se pertencente ao tempo é reconhecer o absurdo do nosso existir perecível. O tempo nos assusta porque descortina nossa própria finitude, nossa própria morte como possibilidade concreta, nossa vida como absurda.

$\mathrm{Na}$ vida cotidiana a finitude aparece mascarada, pois vivemos com preocupações exacerbadas, com o pensamento no futuro, imersos em planos que talvez jamais realizemos. Como observa Guimarães, "[...] não querendo o fim, queremos o futuro"14, por isso, vemos na morte alheia simplesmente um fato exterior, e não uma prévia do nosso destino. Entretanto, o tempo sempre impõe seu horror matemático, sua presença corrosiva: envelhecemos, adoecemos, vislumbramos o fim. E, dessa forma, o caráter temporal da existência une-se à captação da morte como algo palpável, revelando o absurdo: o tempo ilumina aquilo que é mais elementar e definitivo na nossa aventura, aquilo que é inevitável: a morte - a morte que não é senão a carne e "[...] o conteúdo do sentimento absurdo". ${ }^{15}$

Assim, pode-se dizer que a morte é o absurdo. Mas também o é o estranhamento diante do mundo. E o tempo, e a doença, e o envelhecimento. Na verdade, tudo aquilo que parece inumano, que nos excede e que não podemos compreender é o absurdo. É preciso notar, porém, que nada disso "é o absurdo" de forma definitiva, mas apenas a descrição de situações capazes de despertar "[...] sentimentos que podem conter o absurdo. Mesmo acabada a enumeração, não esgotamos o absurdo". ${ }^{16}$

\section{O que fazer com o absurdo?}

Até aqui, vimos que o absurdo possui várias maneiras de se manifestar, todavia, é preciso dizer ainda que essas manifestações talvez representem apenas um momento de luz em meio às repetições cotidianas, quer dizer, pode-se muito bem retornar do absurdo para os "grilhões do inconsciente", como se nada tivesse acontecido. Pode-se, então, encontrar refúgio na esperança, já que ela, assim como "[...] a precipitação no divino ou no eterno, o abandono às ilusões do cotidiano ou da ideia, todas essas telas ocultam o absurdo". ${ }^{17}$

Por outro lado, a partir da experiência do absurdo pode-se também aportar em um despertar definitivo, ou seja, em um movimento de consciência do absurdo do qual não mais se volta. Nesse caso, não haverá mais a possibilidade da esperança ou de qualquer outro ocultamento do absurdo, pois a morte se afirmará como a única certeza: a morte será a certeza absurda e diante dela restará somente uma imensa interrogação. Isso não quer dizer que o homem consciente do absurdo esteja mergulhado no desespero, afinal, para ele não há expectativa de uma solução ou mesmo de uma fuga do absurdo, esse homem "[...] vive do que tem sem especular sobre o que não tem". ${ }^{18}$ 
A partir do despertar definitivo para o absurdo, Camus ${ }^{19}$ apresenta duas possibilidades antagônicas: uma é o suicídio ${ }^{20}$, a outra é o restabelecimento, isto é, a aceitação de uma vida absurda.

Segundo Camus, o suicídio nada mais é do que uma tentativa de solucionar o absurdo, de fugir de sua força, de negá-lo através da morte. Contudo, como explica Onfray, através do suicídio "[...] acreditamos terminar com a absurdidade da vida, enquanto, paradoxalmente, nós a afirmamos, aumentamos sua força e sua potência. A vida é absurda, dar um fim à vida é absurdo". ${ }^{21}$ Quer dizer, suicidar-se não soluciona nem supera o absurdo, apenas aniquila qualquer possibilidade: o homem morre com seu absurdo e não resolve nada. O suicídio é uma tentativa de aniquilar o absurdo que aniquila apenas aquele que faz o absurdo viver. Dessa maneira, a morte voluntária é simplesmente uma tentativa frustrada, é furtar-se ao absurdo, não resolvê-lo, é admitir "[...] que fomos superados pela vida ou que não a entendemos". ${ }^{22}$ Diante disso, o suicídio revela-se como uma forma de fugir à confrontação com o absurdo, de evadir-se; mas não é só isso, é também uma concordância com ele, uma confissão da incapacidade de superá-lo.

Vemos assim que não se pode aniquilar o absurdo; em contrapartida, basta pouco para despertá-lo, para reforçá-lo, para torná-lo ainda mais verdadeiro. Se o suicídio não se mostra como solução viável, só resta ao homem viver com seu absurdo, isto é, tornar-se homem absurdo. O homem absurdo é aquele que se mantém sempre consciente do absurdo, que se liga a ele até o fim, vivendo-o permanentemente. Esse é um caminho sem volta, um caminho que apresenta como única saída a sustentação do absurdo. De tal forma, o homem absurdo reafirma o absurdo sem vãs esperanças, aceitando este mundo e negando o suicídio, afirmando "[...] ao mesmo tempo consciência e recusa da morte"23: viver o absurdo é fazer o absurdo viver, o que também quer dizer contemplá-lo e afastar-se do suicídio; viver o absurdo é jamais conciliar-se com a morte, é não entregar-se voluntariamente a ela, é recusar tudo aquilo que visa atenuar o peso da existência.

Certamente, essa perpétua consciência do absurdo é uma carga demasiado pesada a se carregar. Ainda assim, é necessário que se aprenda a alegrar-se com esse peso, a tirar dele a força para exaurir todas as possibilidades - as do mundo e as nossas. Isso não significa, entretanto, que o homem absurdo esteja disponível a aceitar qualquer coisa, mas que ele se dispõe a examinar todos os caminhos possíveis. Com efeito, sem respostas predefinidas o homem absurdo se permite considerar todas as soluções: para ele nenhuma porta está definitivamente fechada. Nessa perspectiva, aceitar o absurdo é viver plenamente as possibilidades, é viver de forma que o absurdo esteja sempre iluminado, é constantemente vê-lo e confrontá-lo, é torná-lo uma paixão - mas não uma paixão qualquer: uma paixão dilacerante, uma paixão absurda.

Resta-nos, porém, perguntar: como se pode viver essa paixão? 
Para que possamos obter tal resposta é preciso abordar justamente o trágico mito de Sísifo. Como narra Camus, Sísifo foi condenado pelos deuses "[...] a empurrar incessantemente uma rocha até o alto de uma montanha, de onde tornava a cair por seu próprio peso". ${ }^{24}$ Esse era o castigo mais cruel que os deuses poderiam impor a um homem, visto que significava na prática um destino sem saídas, sem esperanças e, sobretudo, sem utilidade nem sentido. Ora, ter de esforçar-se diariamente a fim de rolar uma pedra até o cume de uma montanha, mesmo sabendo que ela forçosamente descerá, representa um suplício inominável, já que todo empenho se dá para nada.

Sendo assim, podemos observar na condenação de Sísifo

[...] todo o esforço de um corpo tenso a erguer a pedra enorme, empurrá-la e ajudá-la a subir uma ladeira cem vezes recomeçada; vemos o rosto crispado, a bochecha colada contra a pedra, o socorro de um ombro que recebe a massa coberta de argila, um pé que a retém, a tensão dos braços, a segurança totalmente humana de duas mãos cheias de terra. Ao final desse prolongado esforço, medido pelo espaço sem céu e pelo tempo sem profundidade, a meta é atingida. Sísifo contempla então a pedra despencando em alguns instantes até esse mundo inferior de onde ele terá que tornar a subi-la até os picos. E volta à planície. ${ }^{25}$

Podemos reconhecer nessa descrição do suplício de Sísifo a perfeita representação do destino do homem: um ser condenado a priori a uma existência sem sentido e sem solução, condenado a carregar o peso de uma tarefa absurda, a rolar uma pedra diariamente. De fato, esse destino nada mais é do que a nossa própria vida. Sísifo é como a maioria dos homens do nosso tempo, trabalhando maquinalmente nas mesmas tarefas, preso a um cotidiano maçante, a um destino fatal.

Entretanto, como sublinha Camus, rolar a pedra montanha acima não é o momento mais importante do mito, não é essa árdua tarefa que distingue Sísifo do homem comum, mas sim a descida, o momento da volta à planície. Com efeito, é no momento da volta nesse momento que se repete todos os dias após o esforço sobrehumano para rolar a pedra morro acima - que Sísifo respira, é na descida que ele pode tomar consciência de seu destino. A tragicidade do mito vem justamente dessa consciência que Sísifo enquanto desce a montanha e respira - consegue ter de seu fardo, pois é a partir daí que ele entende que seu destino é sem esperanças, sem possibilidades de triunfo.

Dessa forma, é ao descer da montanha consciente de sua condição miserável que Sísifo se torna um homem absurdo, dado que é nesse momento que a condenação dos deuses a um destino inútil é superada: Sísifo caminha consciente, por isso, o tormento desaparece, torna-se nada diante de seu desprezo. Sísifo despreza o poder dos deuses, permitindo assim que uma alegria silenciosa brote em seu coração - ele diz não à morte, não aos deuses, e ao fazer isso ele diz sim à vida. Sísifo supera a condenação dos deuses ao reconhecer aquele destino absurdo como seu, ao assumi-lo, ao fazer dele não uma imposição divina, mas uma escolha humana. Como narra Camus, enquanto "[...] 
abandona os cumes e mergulha pouco a pouco nas guaridas dos deuses, Sísifo é superior ao seu destino. É mais forte que sua rocha". ${ }^{26}$

Assim, ao tornar-se senhor do próprio destino, Sísifo não maldiz a rocha, mas faz dela a sua morada; ele se transforma num homem absurdo que assume sua sorte, mesmo consciente do imenso esforço que ela exige. Assumir o próprio destino é assumir as rédeas da própria vida, é contemplá-la como uma criação contínua, como uma obra que só será terminada com a morte. Por conseguinte, ao reconhecer sua sorte - por mais dolorosa que essa possa parecer - Sísifo afirma que tudo está bem: ele está feliz. Segundo Camus, esse "estar bem" com o absurdo, essa felicidade, ecoa

no universo feroz e limitado do homem e ensina que nem tudo foi experimentado até o fim. Ela expulsa deste mundo um deus que havia entrado nele com a insatisfação e o gosto pelas dores inúteis. Faz do destino um assunto humano, que deve ser acertado entre os homens. ${ }^{27}$

Portanto, o homem absurdo é aquele que não se contenta com um destino preestabelecido, mas mergulha nesse destino e faz dele criação sua. $O$ homem dos nossos dias está "[...] jogado numa série de tarefas repetidas e exaustivas", porém, se assim como Sísifo ele toma consciência disso, ele "[...] alcança aquela superioridade sobre seu destino". ${ }^{28} \mathrm{Ou}$ seja, ao tomar consciência de sua sorte e assumi-la, qualquer homem pode se tornar absurdo. Isso significa que, mesmo rolando sua rocha montanha acima, esse homem jamais verá a vida como uma tarefa estéril e fútil, pelo contrário, ele amará essa existência, buscando nela uma felicidade, uma beleza absurda: do alto da montanha o homem absurdo contempla a pedra que inevitavelmente desmorona, mas faz isso como se esse desmoronar fosse fruto do seu desejo - como Sísifo, ele agora respira o absurdo, como Sísifo, ele está feliz.

\section{Criar a partir do absurdo}

Como acabamos de mostrar, Camus acredita que pode haver uma felicidade absurda, ou melhor, ele nos diz que é preciso que haja: "É preciso imaginar Sísifo feliz". ${ }^{29}$ No entanto, essa felicidade só pode ser conquistada por um homem que afirme e sustente uma existência absurda, ou seja, por um homem que, como Sísifo, se mostre capaz de tornarse um homem absurdo. $O$ homem absurdo se mantém em constante tensão, perpetuamente diante do mundo, em contato permanente com o absurdo. Nessa posição, Camus nos diz que tal homem vive uma espécie de "delírio ordenado" ${ }^{30}$, em que recusa a morte e se abre para as possibilidades da vida. A partir disso, o homem absurdo se faz um criador: ele cria a si mesmo, esculpindo seu destino, modelando sua própria existência como uma obra de arte.

Ora, se o homem absurdo recusa a morte e aceita as possibilidades que a vida the oferece criando a partir disso seu próprio destino, o artista - criador por excelência - é 
justamente aquele que consegue também "[...] construir o que aceita, e desprezar aquilo que recusa do mundo". ${ }^{31} \mathrm{O}$ artista é, nessa perspectiva, um homem que cria seu destino a partir do absurdo, mas que, além disso, o recria de uma maneira singular em sua obra. Assim, a criação de uma obra de arte representa para esse homem muito mais do que um simples prazer: ela é uma "[...] oportunidade única de manter sua consciência e de fixar suas aventuras. Criar é viver duas vezes", ${ }^{32}$ é ter a possibilidade de fixar o absurdo, de ter consciência dele, de experimentá-lo novamente e, sobretudo, de reviver uma felicidade absurda. Por isso, como sublinha Melançon, a obra de arte "[...] se situa ao final da descoberta do absurdo e é a alegria por excelência". ${ }^{33}$

Sendo a obra de arte filha do absurdo, ela não buscará solucioná-lo, mas descrevê-lo, funcionando como uma espécie de espelho da existência absurda. Essa essência descritiva da obra garante o afastamento do artista de qualquer pretensão de unificação do vivido através da razão, e, além disso, o mantém em constante contato com o absurdo. A obra de arte é, então, fruto de uma inteligência lúcida que entende sua própria limitação, pois, como explica Camus, para que uma obra de arte ganhe vida "[...] é preciso que o pensamento, na sua forma mais lúcida, esteja inserido nela. Mas, ao mesmo tempo, é preciso que só apareça como inteligência ordenadora". ${ }^{34}$

Certamente, podem existir obras de arte que intentem explicar o absurdo, todavia, elas não se alimentarão do absurdo, mas de uma vã esperança. Como explica Germano: "A arte absurda não almeja nem resolver, nem curar os enigmas humanos, ela os consolida e os assume na síntese da imagem". ${ }^{35}$ Quer dizer, uma obra absurda é uma obra criada por uma inteligência que não busca simplesmente raciocinar o concreto, mas carnalizálo; por isso, a lucidez dessa inteligência não significará a racionalização da obra através de imagens, mas a imaginação daquilo que a razão não dá conta de explicar. ${ }^{36}$ Ora, uma obra de arte pode ordenar e descrever a realidade através de imagens, mas jamais pode saná-la:

[...] a arte absurda não retira sua dignidade de sua função de epifania, ópio ou miragem útil à contemplação desesperançosa de um homem alquebrado. [...] A arte absurda alça sua dignidade de sua lucidez e de seu mergulho interrogante nas representações reivindicadas pela vida. ${ }^{37}$

À vista disso, quanto mais absurda uma obra de arte, menos ela revela: valendo-se do não dito e do por dizer, tal obra apresenta o "[...] subentendido de experiência cuja riqueza se adivinha". ${ }^{38}$ Quer dizer, uma obra de arte verdadeiramente absurda jamais oferece uma justificativa ou uma saída para o absurdo, ao invés disso, ela tenta apontar para ele com certa indiferença, isto é, sem a pretensão de explicar o absurdo, ela simplesmente joga sua luz sobre ele. Isso significa que essa obra de arte absurda essencialmente descritiva - será uma espécie de recriação da realidade "[...] sob a máscara do absurdo". ${ }^{39}$ Tal recriação não será, porém, uma tentativa de aperfeiçoar uma realidade absurda, mas de imitá-la e de representar "[...] um pedaço talhado da experiência, uma faceta do diamante cujo brilho interior se resume sem limitar-se". ${ }^{40}$ 
De tal forma, a arte entendida enquanto recriação, imitação da realidade, não representa a construção de um refúgio contra o absurdo, afinal, assim como Sísifo, o artista que vive uma vida absurda não alimenta esperanças de fugir do seu destino, mas se felicita em vivê-lo, em criá-lo e recriá-lo. Portanto, não sendo nem refúgio nem solução, a obra de arte é uma repercussão do absurdo na consciência dos homens, ou seja, ela é

[...] um fenômeno absurdo [...]. Não oferece uma saída para o mal do espírito. [...] Mas, pela primeira vez, tira o espírito de si mesmo e o coloca diante de outro, não para que se perca, mas para mostrar-Ihe com um dedo preciso o caminho sem saída em que todos estão comprometidos. ${ }^{41}$

Destarte, a arte parece ter o poder de colocar os homens diante do absurdo: ela não quer aniquilar o absurdo, mas descortiná-lo para seu público. Ora, se o artista cria para manter-se frente ao absurdo, a partir da sua criação ele também possibilita a revelação do absurdo a outros homens. Nesse sentido, assim como o estranhamento diante do mundo, o tempo e a morte, a arte também pode conter o absurdo, isto é, ela também é capaz de despertar nos homens o sentimento do absurdo. Com isso, uma obra absurda, mais do que partir do absurdo, intentará dar uma voz a ele, não a fim de solucioná-lo, mas de descrevê-lo, de encarná-lo. Essa obra terá no absurdo não apenas seu ponto de partida, mas, sobretudo, seu horizonte - um horizonte que ela aponta para que outros homens também o vejam.

\section{Fazer do absurdo um samba!}

O samba ainda vai nascer O samba ainda não chegou Caetano Veloso

A partir do que dissemos até aqui sobre a noção do absurdo em Camus, é justamente a capacidade que a arte possui de despertar no homem o sentimento do absurdo que gostaríamos de destacar agora, e para isso propomos uma visão sobre uma obra de arte absurda, isto é, o disco Sambas do absurdo.

A ideia desse disco nasce de um encontro - do cantor e compositor paulista Rodrigo Campos - com o absurdo: "Acho que encontrei o 'absurdo'. Estava me sentindo desconectado, apático em relação às coisas" ${ }^{42}$ - diz Rodrigo em entrevista. Somado a isso, a leitura de $\mathrm{O}$ mito de Sísifo apareceu ao artista como um impulso, como uma inspiração para compor algumas melodias, alguns sambas: "Foi um impacto pra mim ler $\mathrm{O}$ mito de Sísifo [...]. E aí comecei a fazer uns sambas, pensando no livro". ${ }^{43} \mathrm{O}$ resultado foram oito melodias, oito sambas que acharam nos versos de Nuno Ramos, na voz de Juçara Marçal e nos arranjos de Gui Amabis sua completa absurdidade. 
Seguindo esse caminho, o disco se constrói a partir do absurdo, faz dele seu norte e sua forma, sua matéria-prima e sua inspiração central. O absurdo está não só no nome da obra, mas também no título das oito canções, todas chamadas "Absurdo" e numeradas em ordem decrescente - começando com "Absurdo 8" e terminando com "Absurdo 1". A esse respeito, Romulo Fróes destaca que a opção por não dar um título diverso a cada canção, mas diferenciá-las somente por números referentes "[...] à sequência em que foram compostas", acaba reunindo esses sambas "[...] sob um mesmo arcabouço poético"44, sob uma mesma estética do estranhamento. Nesse sentido, a disposição das canções em uma espécie de contagem regressiva parece indicar que o fim se encontra já na primeira canção e que, por outro lado, o início também pode estar na última, ou seja, não há no disco uma pretensão à linearidade, mas uma propensão à desordem, ao absurdo.

De fato, Sambas do absurdo não pretende oferecer uma narrativa linear, fácil, objetiva, em suma, o disco não propõe uma transposição de $O$ mito de Sísifo para o universo do samba. Na verdade, o disco quebra a teoria camusiana e a dissolve em suas várias camadas, a fim de apontar para uma outra direção. Talvez por isso, esse "Absurdo" que dá nome ao disco e às canções - será apenas sugerido pelos versos: a palavra 'absurdo' não aparece em nenhuma das letras, mostrando que não é preciso nomear o absurdo para que ele exista. ${ }^{45}$ Com efeito, as letras do - entre outras coisas - artista plástico e escritor Nuno Ramos não tentam construir ou reconstituir conceitos, e tampouco buscam explicar algo, ao invés disso, elas se referem a temas variados de maneiras variáveis, apresentando sentidos mutáveis e quase sempre desconexos que se alimentam de tudo, e que transformam tudo em absurdo. Nuno não se preocupa tanto em conferir um significado objetivo a seus versos, mas vai brincando com sentidos possíveis, com sentidos múltiplos que vão desde "a coxa duma voz" - em Absurdo 6 até "lábios de fumaça" - em Absurdo 2.

Diante disso, por mais que possamos encontrar pequenas alusões, não haverá nas letras do disco citações diretas ou explicações do ensaio de Camus. Na verdade, não é tanto a teoria camusiana que parece unir as duas obras, mas uma espécie de estupor diante do absurdo e, sobretudo, a tentativa de descrevê-lo para outrem, cada qual se valendo de um clima particular: Camus através de um raciocínio absurdo, Sambas do absurdo através de uma estética absurda. Isso significa que o disco não oferecerá ao ouvinte uma reconstituição didática do absurdo, mas canções estranhas que tem o absurdo entranhado em seus mais ínfimos detalhes: o absurdo vira samba, pois cada canção vira um absurdo. Por isso, enquanto o ensaio de Camus trata o absurdo através de imagens extremas, porém palpáveis - como, por exemplo, a do amante, do comediante e do aventureiro -, Sambas do absurdo aborda o absurdo sempre oscilando entre representações de situações banais do cotidiano - como nos versos que fecham o disco: "passa minha senha, passa/ quem riscou meu carro?" - e imagens impalpáveis como "e o chão laialaiava" de Absurdo 2. 
Com isso, Nuno Ramos vai construindo pequenas e duras imagens em versos que nem sempre representam situações e heróis que lidam com o absurdo de uma forma exemplar, mas que muitas vezes se contentam em colocar questões absurdas, em buscar uma espécie de contato conosco, como que esperando uma resposta que nunca vem. Além disso, esses heróis nunca se revelam totalmente, eles são como vozes sem rosto: é "inseto ou é menina" (Absurdo 8), é "bicho, pedra, homem, planta" (Absurdo 7), é "bunda, peito, flora, fauna" (Absurdo 2)? Ainda nessa perspectiva, Guilherme Werneck acrescenta que os versos de Nuno Ramos parecem estar sempre em aberto, como se as conclusões nunca fossem definitivas, mas "[...] antes enganadoras, pausas" ${ }^{46}$

É justamente nessas pausas, nesses espaços construídos entre a narrativa e a abstração, entre a morte e o gozo, entre o inerte e o humano, entre o questionamento e a afirmação, que os pequenos absurdos do disco se formam: o absurdo de "quem nasce da costela", "no Éden", mas acaba "maluco/sem teto" - em Absurdo 8; o absurdo que vem da "bisonha/ luz da tevê" - em Absurdo 6 - e da "voz do tubo prateado" - em Absurdo 1; o absurdo de um questionamento sem resposta possível - "morri criança, nasci pra que" - em Absurdo 7; entre tantos outros.

Nesse sentido, as letras de Nuno Ramos apresentam narrativas que se esfacelam e se transformam rapidamente em outra coisa, mostrando, então, que o absurdo não é apenas apontado como algo exterior, mas é parte formal dos versos, da maneira como são compostos, como se relacionam com as melodias e, principalmente, como são cantados. Seja através de perguntas existenciais ou de diálogos irrealizáveis, de narrativas esfaceladas ou de afirmações fortes, de representações de situações banais ou extraordinárias, as letras de Sambas do absurdo sempre acabam contribuindo para que o absurdo aflore, isto é, para que possamos provar através deles o sentimento do absurdo.

Dito isso, é imprescindível destacar a interpretação de Juçara Marçal, visto que as letras de Nuno Ramos só conseguem alcançar tamanha absurdidade graças ao sentido que a voz da cantora Ihes confere. Juçara possui um canto múltiplo, podendo variar em uma mesma obra entre a rispidez e o desespero, entre a tensão e a violência, entre a ironia e a explosão - como nota Walter Garcia ${ }^{47}$ a respeito do primeiro disco solo da cantora, Encarnado. ${ }^{48}$ Porém, em Sambas do absurdo, Juçara Marçal não apresenta tantas variações, e sim uma certa constância, o que acaba conferindo à sua voz uma espécie de impessoalidade que pouco se altera nas oito canções do disco. A cantora contém sua explosão, oferecendo seu canto para que as vozes sem rosto das letras de Nuno Ramos possam falar. Romulo Fróes resume muito bem o canto de Juçara Marçal em Sambas do absurdo:

Um ar toma conta de sua voz, tornando-a um tanto distante, parece vir de um lugar de fora da canção. Enxergo nessa distância, nessa quase "não-interpretação", talvez o 
partido que encontrou para interpretar esse repertório. Mais do que cantar, Juçara parece narrar as canções. [...] Como narradora, Juçara encontrou uma articulação possível para conjugar a polifonia de vozes que compõe o disco. ${ }^{49}$

Ora, se a interpretação de Juçara Marçal se mostra articulada, porém distante, isso não significa que ela tenha pouca importância dentro da obra, pelo contrário, é justamente nessa contenção que ela se destaca: ao retirar da sua voz qualquer emoção estranha à canção ela permite que o absurdo de cada canção se realize no seu canto. A voz de Juçara só reforça toda absurdidade presente nas letras, de sorte que sua voz concede a cada canção um "[...] equilíbrio entre a evidência e o lirismo", um equilíbrio que permite a quem escuta "[...] aceder ao mesmo tempo à emoção e à clareza" ${ }^{50}$ de cada verso, de cada palavra.

É imprescindível notar ainda que a interpretação de Juçara Marçal se mostra dessa maneira não apenas devido às letras de Nuno Ramos, mas também devido à relação nem sempre confortável que as palavras do artista plástico mantêm com as melodias de Rodrigo Campos. De fato, os versos de Nuno não estão sempre em confluência com as melodias de Rodrigo: em alguns momentos há certo encaixe, em outros, no entanto, os versos seguem numa velocidade própria, apresentando uma voracidade que quase atropela a melodia, que visa ocupar todos os seus espaços, falando até que a última nota desapareça. É como se letra e melodia se deslocassem de uma maneira própria, sem necessariamente preocupar-se um com o outro, gerando assim encontros e estranhamentos durante uma mesma canção. Por essa razão, como ressalta Romulo Fróes, em Sambas do absurdo o trabalho de ambos se confronta e se modifica: "Rodrigo com suas melodias claras e precisas, dando ritmo à profusão de imagens criadas por Nuno, corrigindo seu trajeto acidentado; Nuno criando tensões com a clareza de Rodrigo, provocando desvios em seu rigor formal".$^{51}$

Deve-se notar, porém, que se, por um lado, as melodias de Rodrigo Campos são claras, por outro, elas não são estruturadas enquanto sambas em um sentido tradicional, mas apresentam elementos não muito comuns ao gênero. ${ }^{52} \mathrm{~A}$ esse respeito, Werneck afirma que há um caráter de não-resolução nas melodias, o que cria a expectativa por uma parte que nunca chega, e, quando as melodias apresentam duas partes, "[...] são só tensão sobre tensão, ou, quando apresentam refrães, vêm em uma embalagem menor de cortar os pulsos". ${ }^{33}$ Em consequência disso, mesmo nas levadas típicas do samba, apresentadas pelo cavaquinho de Rodrigo Campos, não encontraremos algo tradicional, mas uma progressão peculiar que se desenvolve cheia de espaços, como uma espécie de solo interminável.

Assim, deixando espaços em sua progressão, as melodias de Rodrigo Campos sublinham toda tragicidade absurda presente nas letras de Nuno Ramos. De outra parte, as letras de Nuno Ramos destacam que os sambas de Rodrigo Campos não são convencionais, mostrando que eles deixam de lado elementos característicos do 
gênero54: Rodrigo Campos faz um samba "[...] pra não ter de sambar" (Absurdo 8), uma espécie de "[...] samba dentro duma máscara" (Absurdo 2) que assume todo o risco que isso comporta e afirma: "pode deixar que eu mesmo canto aialaiá eu mesmo sambo/ aialaiá eu mesmo tento/ [...] a minha laia o meu pagode, eu danço eu manso eu mesmo toco" (Absurdo 1).

Mas por que esse estranhamento com o samba se impõe em Sambas do absurdo, se esse gênero parece perfeito para revelar o absurdo? Ora, dentro da tradição do samba não faltam obras profundas capazes de revelar os dramas e as absurdidades da vida. Pensemos em Cartola, Noel Rosa, Wilson Moreira, Paulinho da Viola, Nelson Cavaquinho, entre tantos outros que abordaram a morte, o envelhecimento, o tempo, etc. ${ }^{55}$ Por que então estranhar-se com essa tradição?

De fato, Rodrigo Campos ${ }^{56}$ reconhece essa capacidade do samba, esse seu lado existencial, essa elasticidade que lhe permite falar de tudo; mais que isso, ele utilizará justamente esses elementos a fim de provocar um estranhamento no ouvinte, buscando um afastamento do samba de dentro dele, operando um deslocamento em relação ao gênero para tornar-se algo absurdo se visto apenas desse ponto de vista. Quer dizer, o estranhamento, o afastamento do samba não é casual, mas visa provocar um estranhamento no ouvinte, já que ele não encontra no disco aquilo que se espera de um samba, mas se depara com uma forma modificada, isto é, absurda do samba.

Aliás, um elemento que contribui sobremaneira para esse distanciamento é a presença dos arranjos de Gui Amabis. Tais arranjos se misturam às melodias de Rodrigo Campos, anuviando ainda mais a possibilidade do samba tradicional. Amabis utiliza emulações eletrônicas advindas de um sampler a fim de atravessar algumas melodias, de acompanhar outras, mas, sobretudo, de jamais deixar que a sonoridade das canções permaneça totalmente confortável. Como escreve Romulo Fróes, as melodias de Rodrigo Campos de alguma forma ainda "[...] carregam consigo a sintaxe do [...]" samba, porém os arranjos de Gui Amabis atuam "[...] subvertendo a utilização de instrumentos naturalmente associados a ele" 57 :

Deste modo, o sample de um tímpano é reconstruído para reproduzir a pulsação do surdo. Uma caixa com seu timbre saturado reproduz a batida de um tamborim e um arranjo de cordas reprocessado lembra um ataque no prato de uma bateria. ${ }^{58}$

Dessa forma, Gui Amabis vai preenchendo os espaços deixados por Rodrigo nas melodias, ocupando-os muitas vezes quase que absolutamente com emulações de sopros, percussões e cordas. Em Absurdo 6, por exemplo, os samples dividem espaço com o cavaquinho, aparecendo em vários momentos da canção em primeiro plano. Já em Absurdo 5 que, como nota Werneck, tem cara de samba, "[...] Rodrigo faz a levada em modo menor e lá no fundo do mix o sample de Gui traz uma segunda. Isso cria uma dissonância sutil, que não chega a confrontar a canção, mas aprofunda seu campo". ${ }^{59}$ 
Portanto, se as melodias de Rodrigo Campos já são em si mesmas pouco tradicionais, elas ainda apresentam algumas marcas típicas do samba, mas o choque provocado pelos arranjos de Gui Amabis não deixa qualquer dúvida de que a intenção de Sambas do absurdo é tirar o ouvinte de sua zona de conforto. Por isso, seus arranjos desconcertam tanto as melodias, fazendo com que cada canção se mova para uma direção, criando um clima que escapa ao que estamos acostumados, uma atmosfera que aponta para uma interação e um confronto - não somente interno ao disco, mas também entre a obra e seu público.

Assim, poderíamos dizer que Sambas do absurdo é samba sem sê-lo tradicionalmente: é samba e, simultaneamente, não é. O disco segue e recusa a tradição do samba, embaralhando, perturbando, ou mesmo negando essa tradição, como se cada "Absurdo" quisesse jogar com o gênero, flertar com ele, sem jamais entregar-se totalmente. Aliás, Sambas do absurdo não se entrega nem ao samba, nem a nós, pois a obra se constrói sobre um perpétuo conflito: seja entre as letras e as melodias, entre as melodias e o arranjo, entre tudo isso e a tradição ou entre a obra e o ouvinte. Rodrigo Campos apresenta um samba que não é samba; Nuno Ramos oferece letras despedaçadas que parecem incompletas; Juçara Marçal canta contida, como quem desaparece sem revelar muito; e Gui Amabis orquestra todo esse caos de uma forma ainda mais caótica. Com isso, através de suas letras, melodias, interpretações e arranjos, o disco consegue perturbar a audição do público, causando nele certo estranhamento, e, quem sabe, despertando nele o sentimento do absurdo.

\section{Conclusão}

O disco Sambas do absurdo apresenta uma forma singular de lidar com o absurdo, assumindo-o em sua estética e encontrando nele um sentido. $O$ disco não tem a mínima pretensão de superar o absurdo, mas procura assumi-lo em sua forma, fazendo-se assim obra absurda, obra que não salva, mas que busca revelar - a sua maneira - o sentimento do absurdo. Com isso, Sambas do absurdo procura não apenas partir do absurdo, mas encarná-lo: multiplicando paradoxos, reforçando contradições e desconcertando seu ouvinte. Em consequência disso, buscar somente uma relação de parentesco entre a teoria do absurdo exposta em O mito de Sísifo e as canções de Sambas do absurdo é limitar-se a ver algumas poucas referências, algumas alusões que se revelam quase sem importância diante daquilo que essa obra tem a oferecer em si mesma.

Então, se encontramos nesses "sambas" alguns vestígios do pensamento absurdo, não há neles a pretensão, ou melhor, a preocupação de oferecer as mesmas conclusões de Camus. Aliás, a conclusão não parece o mais importante para o disco: Sambas do absurdo não se propõe a resolver o paradoxo do absurdo, mas a alargá-lo, de sorte que ele acaba por restaurá-lo, renová-lo a cada canção. Nesse sentido, as palavras de 
Camus são perfeitas para descrever o disco, já que essa obra talvez "[...] tenha menos importância em si mesma do que na prova que exige de um homem e a oportunidade que the oferece para superar seus fantasmas e se aproximar um pouco mais da sua realidade". ${ }^{60}$

\section{* Vinicus Xavier Hoste é doutorando em filosofia pela UFSCar.}

${ }^{1}$ CAMPOS, R.; MARÇAL, J.; AMABIS, G. Sambas do absurdo. São Paulo: YB Music, 2017. Disponível em: <http://rodrigocampos.art.br/>.

${ }^{2}$ CAMUS, A. O mito de Sísifo. Rio de Janeiro: Record, 2010, p. 112.

${ }^{3}$ GERMANO, E. O pensamento dos limites: contingência e engajamento em Albert Camus. 2007, 498 f. Tese (Doutorado em Filosofia) - Programa de Pós-Graduação em Filosofia do Departamento de Filosofia, Letras e Ciências Humanas da Universidade de São Paulo, São Paulo, 2007, p. 183.

${ }^{4}$ Os exemplos utilizados por Camus vão desde Dom Juan a Dostoievsky, passando por Kafka e Melville, sem esquecer o próprio Sísifo.

${ }^{5}$ ONFRAY, M. L'ordre libertaire: la vie philosophique de Albert Camus. Roubaix: Flammarion, 2012, p. 186, tradução nossa.

${ }^{6}$ Ibidem, p. 186, tradução nossa.

${ }^{7}$ CAMUS, A. Op. cit., p. 41.

${ }^{8}$ GUIMARÃES, C. E. As dimensões do homem: mundo, absurdo e revolta (Ensaio sobre a filosofia de Albert Camus). Rio de Janeiro: Paz e Terra, 1971, p. 53.

${ }^{9}$ CAMUS, A. Op. cit., p. 27.

${ }^{10}$ Ibidem, p. 35.

${ }^{11}$ Ibidem, p. 34.

12 Ibidem, p. 50.

${ }^{13}$ Ibidem, p. 28.

${ }^{14}$ GUIMARÃES, C. E. Op. cit., p. 53.

${ }^{15}$ CAMUS, A. Op. cit., p. 30.

${ }^{16}$ Ibidem, p. 28, nota 1.

${ }^{17}$ Ibidem, p. 105.

${ }^{18}$ Ibidem, p. 106.

19 Ibidem, p. 27.

${ }^{20}$ O mito de Sísifo não nos fala unicamente do absurdo. Na verdade, antes de abordá-lo, Camus inicia sua reflexão tratando do problema do suicídio. Para ele, o único problema filosoficamente sério é esse: "Julgar se a vida vale ou não vale a pena ser vivida é responder à pergunta fundamental da filosofia". Segundo Camus, todos os problemas debatidos pela tradição filosófica se tornam supérfluos diante desta questão essencial: vale a pena viver? Essa pergunta, contrariamente aos questionamentos filosóficos metafísicos, coloca a própria vida em questão de uma maneira fatal, por isso, ela se torna a mais fundamental das perguntas. A aspiração ao suicídio acontece a partir de um divórcio entre o homem e o mundo, de uma separação que não é senão a apreensão da absurdidade da existência, ou melhor, do sentimento do absurdo. Camus 
nos revela assim a ligação entre o absurdo e o suicídio, mostrando-nos que, a princípio, o suicídio aparece enquanto uma solução possível para o absurdo. Cf. CAMUS, A. Op. cit., p. 17.

${ }^{21}$ ONFRAY, M. Op. cit., p. 210.

${ }^{22}$ CAMUS, A. Op. cit., p. 19.

${ }^{23}$ Ibidem, p. 66.

${ }^{24}$ Ibidem, p. 138.

${ }^{25}$ Ibidem, p. 138.

${ }^{26}$ Ibidem, p. 139.

${ }^{27}$ Ibidem, p. 140.

${ }^{28}$ GUIMARÃES, C. E. Op. cit., p. 60.

${ }^{29}$ CAMUS, A. Op. cit., p. 141.

${ }^{30}$ Ibidem, p. 110.

${ }^{31}$ SILVA, F. L. Ética e literatura em Sartre. São Paulo: UNESP, 2004, p. 228.

${ }^{32}$ CAMUS, A. Op. cit., p. 110.

${ }^{33}$ MELANÇON, M. J. Albert Camus: Analyse de sa pensé. Suiça: Les Éditions universitaire Fribourg, 1976, p. 50.

${ }^{34}$ CAMUS, A. Op. cit., p. 113.

${ }^{35}$ GERMANO, E. Op. cit., p. 181.

${ }^{36}$ Em O mito de Sísifo, Camus nos fala, por exemplo, que Moby Dick de Melville é uma obra absurda, que no romance Os demônios, de Dostoievski, Kirilov é um personagem absurdo, e que a obra de Kafka coloca o problema do absurdo. Para além da literatura, Camus afirma ainda que na pintura e na escultura "reina sozinha a descrição em sua esplêndida modéstia", enquanto na música impera uma gratuidade matemática, que nada nos ensina, mas nos dá uma sensação pura, e que o "[...] homem absurdo reconhece como suas essas harmonias". Por tal razão, tais artes se revelam ainda mais propícias a sustentar o absurdo, já que não carregam consigo a tentação da explicação, da resolução do absurdo. Cf. CAMUS, A. Op. cit., p. 114.

${ }^{37}$ GERMANO, E. Op. cit., p. 182.

${ }^{38}$ CAMUS, A. Op. cit., p. 113.

${ }^{39}$ Ibidem, p. 110.

40 Ibidem, p. 113.

${ }^{41}$ Ibidem, p. 111.

${ }^{42}$ AZEVEDO, V. "Rodrigo Campos, Gui Amabis e Juçara Marçal mostram os 'Sambas do absurdo' no Sesc Pompeia". In: Folha de São Paulo (On-line). São Paulo, 2017, p. 1. Disponível em: $<$ https://bit.ly/2yJr9lg>. Acesso em 02 de setembro de 2017.

${ }^{43}$ REINA, A.; CARVALHO, P. "Sambas do absurdo partem de Camus para questionar a tradição". In: Bravo! (On-line). São Paulo, 2017, p. 1. Disponível em: <https://bit.ly/2K8botq>. Acesso em 05 de agosto de 2017.

${ }^{44}$ FRÓES, R. "Manhã sem serventia". In: Outros críticos (On-line). Pernambuco, 2017, p. 1. Disponível em: <http://outroscriticos.com/manha-sem-serventia/>. Acesso em 17 de junho de 2017.

${ }^{45}$ Certamente, podem-se encontrar nas letras das canções algumas correspondências com o ensaio de Camus, como, por exemplo, nos versos de Absurdo 8: "nascia na montanha/a manhã 
sem serventia". Tais versos podem ser interpretados como uma referência a Sísifo, ao seu suplício em ver montanha que deve ser vencida. No entanto, o Sísifo de Sambas do Absurdo parece encontrar seu sentido não na pedra, no esforço, mas na repetição do gozo: em um gozo sexual que é, ao mesmo tempo, um gozo musical, um gozo no samba. Sendo assim, a manhã sem serventia que nasce na montanha "[...] só serve pra gozar mais/ pra não ter, pra não ter, pra não ter de acabar/ de enfiar, de enfiar, de enfiar, de enfiar/ o dedo ali/ o pau no som [...]".

${ }^{46}$ WERNECK, G. "Prazer absurdo". In: Bravo! (On-line). São Paulo, 2017, p. 1. Disponível em: $<$ https://bit.ly/2MT50UN>. Acesso em 07 de agosto de 2017.

${ }^{47}$ GARCIA, W. "Nota sobre o disco Encarnado de Juçara Marçal (2014)". In: Revista USP. São Paulo, n.111, 2016, p. 65. Disponível em: <https://www.revistas.usp.br/revusp/article/view/127600/124650>. Acesso em 13 de agosto de 2017.

48 MARÇAL, J. Encarnado. São Paulo: Independente, 2014. Disponível em: $<$ https://www.youtube.com/watch?v=18p5_PiPk8E $>$.

${ }^{49}$ FRÓES, R. Op. cit., p. 1.

${ }^{50}$ CAMUS, A. Op. cit., p. 18.

${ }^{51}$ FRÓES, R. Op. cit., p. 1.

${ }^{52}$ Em Absurdo 5, por exemplo, o cavaquinho de Rodrigo Campos dá um toque de samba à melodia, sem que haja, contudo, um pertencimento total. Já em Absurdo 3 a redundância característica do samba está presente na estrutura da melodia, que se constrói com base em dois refrães. Esse samba, entretanto, é tocado com a guitarra - instrumento estranho ao samba - e, além disso, a estrutura aparece sutilmente mascarada pelas palavras de Nuno Ramos, que transformam a repetição melódica em uma progressão minimalista.

${ }^{53}$ WERNECK, G. Op. cit., p. 1.

${ }^{54}$ Aliás, as letras de Nuno são também plenas de referências ao samba tradicional: seja abusando das repetições em Absurdo 8 e em Absurdo 1, se apropriando das variações do clássico "laialaiá" em Absurdo 1, ou deturpando os versos de "Águas de março" em Absurdo 2 - o "É pau, é pedra, é o fim do caminho/ É um resto de toco, é um pouco sozinho" de Tom Jobim, se transforma em "é pau/ pedrada/ no meu/ caminho/ um resto/ de toco/ um corpo/ sozinho".

${ }^{55}$ Em seu ensaio "Rugas - sobre Nelson Cavaquinho", por exemplo, Nuno Ramos nos mostra quão absurdo o samba pode ser. Em sua visão, a obra de Nelson Cavaquinho representa "[...] nosso contato imediato com aquilo que deu profundamente errado em nós, sem remissão a nenhum outro: internacionalização, desejo, cosmopolitismo. Consegue sublimar nosso fracasso sem aludir à 'vida que podia ter sido e que não foi'. [...] Em Nelson, a vida é o que é e, num certo sentido, aquilo que sempre foi. Por isso, não carrega ansiedade nem projeto. Parece tão desejável quanto a morte". Cf. RAMOS, N. "Rugas - sobre Nelson Cavaquinho". In: Serrote (on-line), n. 1, 2009, p. 2. Disponível em: <http://www.revistaserrote.com.br/2011/06/rugas-sobre-nelson-cavaquinho/>. Acesso em 23 de setembro de 2017.

${ }^{56}$ REINA, A.; CARVALHO, P. Op. cit., p. 1.

${ }^{57}$ FRÓES, R. Op. cit., p. 1.

58 Ibidem, p. 1.

${ }^{59}$ WERNECK, G. Op. cit., p. 1.

${ }^{60}$ CAMUS, A. Op. cit., p. 68. 